\title{
LA CONTRIBUCIÓN DE LA PROCURACIÓN DE ORIHUELA EN LA CONQUISTA DE CERDEÑA
}

\author{
Juan Antonio BARRIO BARRIO \\ José Vicente CABEZUELO PLIEGO \\ José HINOJOSA MONTALVO \\ Universidad de Alicante
}

La infeudación del «Regnum Sardiniae et Corsicae» por la Santa Sede a Jaime II iniciaba la intervención de los monarcas aragoneses en la isla, que se prolongó durante las centurias posteriores y que generaron diversas expediciones para someter las frecuentes rebeliones sardas, forzando a la Corona a exigir contribuciones económicas a sus súbditos para llevarlas a cabo y mantener la paz, tarea que no siempre fue fácil de conseguir.

En el marco de la celebración del séptimo centenario de la conquista del reino de Murcia por Jaime II y dentro de la recuperación de la figura del "rey Justo", los autores de esta comunicación pretendemos poner de relieve con esta aportación el nivel de participación de las villas de la Procuración de Orihuela en la conquista sarda y las repercusiones que ésta tuvo en las tierras alicantinas, tema que hasta ahora ha pasado prácticamente desapercibido para los historiadores de la región.

Cuando a principios de la década de 1320 Jaime II inició los preparativos para el asalto final a las islas de Córcega y Cerdeña, se arbitraron por parte de la Corona fórmulas que lograsen una participación efectiva de todas las comunidades del reino de Valencia. Una de las vías utilizada habitualmente era, como es sabido, la solicitud de subvenciones, teóricamente acordes a la capacidad económica de cada una de las localidades, que como contrapartida solían obtener privilegios y exenciones que a larga permitían cubrir el capital desembolsado, generalmente importante.

En el reino de Valencia, al igual que en Aragón, fue el infante Alfonso el encargado de conseguir de los valencianos tales aportes económicos, que en esta primera oca- 
sión podemos calificar de generosos, al menos en lo que se refiere a la capital del reino, que aportó nada menos que 350.000 sueldos reales de Valencia (17.500 libras), mientras que Orihuela, a la sazón villa, contribuyó en 1322 con 20.000 sueldos a la empresa sarda, recibiendo en recompensa diversos privilegios al tiempo que viendo confirmados otros anteriores por parte de Jaime II, predominando los que tienen un claro contenido económico o político, siempre en beneficio del municipio y de sus habitantes. Entre ellos figuran los expedidos el uno de marzo de 1322, en el primero de los cuales el monarca declaraba a los vecinos y sus mercancías francos del pago de lezdas en todos los territorios de la Corona de Aragón ${ }^{1}$. En otro de ellos prohibía a los oficiales reales del municipio todo acto de compraventa o donación del suelo que conllevara la reducción o alteración de las plazas, calles y mercados, en detrimento de la utilidad pública'; mientras que en el último Jaime II confirmaba los fueros, libertades, franquicias y libertades que habian disfrutado hasta entonces los vecinos de Orihuela ${ }^{3}$. Este último privilegio era particularmente importante para los oriolanos, incorporados de forma definitiva a la Corona de Aragón y al reino de Valencia no hacía muchos años, tras la sentencia arbitral de Torrellas en 1304, pero conservando también sus fueros peculiares de la etapa de dominio castellano, ahora ratificados. Esta fue una característica común a las distintas localidades que integraban la Procuración de Orihuela: Alicante, Elche y Guardamar, que los reyes respetaron siempre, la coexistencia de los Furs de València con las particularidades locales. De nuevo el 31 de mayo de 1322 el infante Alfonso confirmará a los oriolanos todos estos fueros otorgados por su padre, Jaime $\mathrm{II}^{4}$, mientras que les ratificaba la inmunidad de todo tipo de impuestos y servicios reales, como portazgos, lezdas, aduanas, etc. ${ }^{5}$. Los privilegios dados a Orihuela son, por lo demás, similares a los del resto de las villas de la Procuración, y ese mismo día el infante Alfonso confirmaba a Elche los fueros, franquicias y demás privilegios concedidos por Jaime II en compensación por la ayuda económica para la empresa de Cerdeña ${ }^{6}$.

Vemos pues un claro interés por parte de los municipios de obtener a cambio de tan elevado subsidio importantes compensaciones en el terreno de lo económico, y es en este contexto en el que hay que situar el nacimiento de una de las principales imposiciones que gravarán en lo económico a los ciudadanos de la procuración de Orihuela, y también del reino de Valencia: nos referimos a las sisas ${ }^{7}$. La consolidación del sistema impositivo de las sisas en el mediodía del reino de Valencia hay que si-

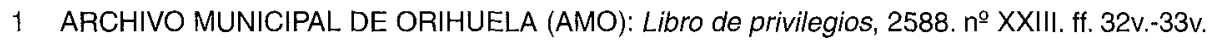
ARCHIVO HISTÓRICO NACIONAL (AHN): Códice 1368-B, Privilegia per Serenissimos Reges ciuitati Oriole concesa, ff. 62v.-64r.

2 AMO: Libro de Privilegios, 2588. fff. 33v.-34r. AHN: Privilegia, 1268 B. ff. 64r.-65r,

3 AMO: Libro de Privilegios, 2588. no XXV. f. 34r. AHN: Privilegia, 1368 B. ff. 65r.-66r.

4 AMO: Libro de Privilegios, 2588, $n^{\circ}$ II, f. 41r.

5 AMO: Libro de Privilegios, $1368 \mathrm{~B}, \mathrm{ff} .78 \mathrm{v} .-80 \mathrm{r}$.

6 ARCHIVO MUNICIPAL DE ELCHE (AME): Armario 2, Páginas de Oro, № 11. (1322, mayo, 31).

7 BARRIO BARRIO, J.A.: El ejercicio del poder en un municipio medieval: Orihuela 1308-1479. Alicante, 1993, (tesis microfichada). 
tuarla en el privilegio concedido por Jaime II a finales del año 1321, por el que ordenaba que todas las ciudades y villas que contribuyesen con subvenciones para la campaña de Córcega y Cerdeña debían recibir licencias para imponer tributos e impuestos con el fin de poder reunir fácilmente dichas cantidades y autorizaba al infante Alfonso para otorgar en su nombre privilegios de concesión de tributos ${ }^{8}$. Se sitúa, por tanto, en relación con el problema de la conquista de Cerdeña (1323-1324), y quedó plasmado en las veinte galeras que se armaron en la ciudad de Valencia con las subvenciones que aportó esta ciudad, 350.000 sueldos, y las del resto de las ciudades del reino ${ }^{9}$.

Tal franquicia, que al principio tenía carácter temporal, gravaba la compra y venta de determinados productos en el mercado local, sobre todo los artículos básicos del consumo: pan, vino, carne, pescado, etc. y en la Procuración oriolana fueron autorizadas a imponerlas Alicante, Elche y Guardamar el uno de abril de $1322^{10}$. La primera dió una ayuda económica al monarca de 12.000 sueldos, mientras que la de Elche fue de 8.000 sueldos y de 6.000 la de Guardamar. El 15 de febrero de 1324 vieron prorrogadas dicha concesión de sisas cada una de las tres mencionadas villas en quince, seis y cinco años respectivamente. ${ }^{11}$ En dicho año Alicante se excusaba ante el procurador y el baile general de esa tierra acerca de su participación en tal subsidio. Exponía "el extravío de sus negocios" que había producido las luchas entre el rey Roberto y los genoveses, por lo que solicitaba se rebajase su participación hasta los mencionados 12.000 sueldos así como franquicias comerciales en Córcega y Cerdeña, como ciudades de la talla de Barcelona y Valencia ${ }^{12}$.

Orihuela, que había recibido el privilegio de la sisa en 1312, obtuvo el 31 de mayo de 1322 una prórroga de quince años del mencionado impuesto ${ }^{13}$. En 1324 Jaime II prorrogó a estas villas la duración de la concesión de las sisas durante algunos años más $^{14}$. La ciudad de Valencia, como premio a su importante aportación, recibió en 1322 del infante Alfonso la concesión de un importante privilegio para poder fijar una serie amplia de imposiciones sobre la navegación, el comercio y sobre la compraventa de

8 AO, Priv. I, Alfonso IV., p. 215. (1321, diciembre, 10).

9 RUBIO VELA, A.: «El segle XIV», en Història del País Valencià. De la conquesta a la Federació Hispànica. Vol. II. Barcelona, 1989, pp. 197-198. Acerca de la conquista de Cerdeña cfr. ARRIBAS PALAU, A.: La conquista de Cerdeña por Jaime Il de Aragón. Barcelona, 1952.

10 HINOJOSA MONTALVO J., BARRIO BARRIO, J.A.: "Las sisas en la Gobernación de Orihuela durante la Baja Edad Media", Anuario de Estudios Medievales, 22, Barcelona, 1992, pp. 535-579.

11 ACA, C, reg. 225, f. 191r.

12 ARRIBAS PALAU, A.: La conquista de Cerdeña ..., p. 181.

13 ESTAL, J.M.: Colección documental ..., doc. n.o 92. (1322, mayo, 31).

14 Ibídem, doc. n. 99. Concesión a Orihuela. Doc. n.ำ100. Concesión a Alicante. Doc. n.ำ101. Concesión a Elche. Doc. n. 102. Concesión a Guardamar. Todos los documentos tienen la misma fecha, 1324, febrero, 15. La prórroga de estos años se añadía a los quince ya otorgados. Orihuela cinco años, Elche seis, y Guardamar cinco. Alicante recibió un privilegio especial para poder duplicar la cuantía del valor de la sisa por el tiempo ya concedido de quince años. Finalmente, tras los privilegios de 1324 la concesión de las sisas en la Gobernación quedaba así: Alicante (1322-1337), Orihuela (1322-1342), Guardamar (1322-1342) y Elche (1322-1343). 
determinados productos ${ }^{15}$. La contribución final de las ciudades del reino de Valencia se cifró en los 350.000 sueldos aportados por la capital y los 46.000 de las villas de la Procuración de Orihuela ${ }^{16}$.

La solicitud de vituallas también era habitual y Orihuela, Elche, Guardamar y Alicante, las principales poblaciones del meridión valenciano, fueron requeridas por Jaime II a fin de que prestasen un subsidio en trigo y cebada para la conquista de Cerdeña ${ }^{17}$, lo que provocó las quejas de estas localidades, dado que su política de abastecimiento del mercado local, siempre en frágil equilibrio, podía quedar gravemente afectada. Recordemos que Jaime Il había solicitado en 1321 a la Procuración de Orihuela un subsidio de 3.000 cahices de cereal, cantidad que el procurador Simó de Bell.lloch debía distribuir entre las comunidades. Si bien, las distintas poblaciones se mostraron reticentes en satisfacer tal cantidad por varias razones. Argumentaban lo excesivo de la misma - no se recogía ni en dos años-, que las mejores tierras de la huerta se encontraban en poder de los mudéjares «que alli son poblats», la incertidumbre de los años venideros, así como que todo el peso del subsidio recaía sobre la ciudad, ya que ni caballeros ni hòmens de paratje contribuirían al poseer privilegio de exención. Todas las comunidades expusieron este razonamiento, que debía ser más que cierto ya que fue ratificado por el propio Simó de Bell.lloch ${ }^{18}$.

Además de la población cristiana, para entonces ya mayoritaria en los núcleos urbanos de la Procuración oriolana, contribuyeron también al subsidio de Cerdeña moros y judíos en proporción que por el momento desconocemos. De los judíos tan sólo nos ha quedado una noticia de julio de 1322 por la que sabemos que el rey notificó al baile general del reino, Jaume Andreu, que había autorizado a la aljama judía de Orihuela a imponer sisas con el fin de que pudiera recaudar la mencionada ayuda y otras cantidades que se le habían solicitado a la aljama ${ }^{19}$. Como vemos, las soluciones dadas por los hebreos son las mismas que las de los cristianos, la aplicación de sisas, algo normal si tenemos en cuenta que la minoría judía vivía inserta dentro del sistema feudal cristiano. El problema para ellos era que esta carga solicitada para la conquista de Cerdeña se añadía a las continuas y numerosas peticiones monetarias que continuamente les estaba haciendo el rey, para quienes los judíos no dejaban de ser «nostre tresor», con lo cual la situación económica de las aljamas solía ser bastante precaria.

No menos dramática debía ser la situación de los mudéjares, ya en un proceso de retroceso demográfico claramente perceptible en el primer tercio del siglo XIV como consecuencia de las emigraciones hacia el reino de Granada y que pocos años después se acentuaría con las expediciones del caudillo Ridwan en 1331 y 1332 . Al menos

15 AO, Priv. I y II. Privilegios del infante Alfonso. (1322, febrero, 26), pp. 215-218.

16 ARRIBAS PALAU, A.: La conquista de Cerdeña ..., p. 185.

17 ARRIBAS PALAU, A.: La conquista de Cerdeña ..., p. 54.

18 ARRIBAS PALAU, A.: La conquista de Cerdeña ..., p. 190. Cf. docs. 125bis y 126 del de Estal Alicante de villa a ciudad.

19 ACA, C, reg. 222, f. 105r-v. (1322, julio, 21). 
así parece deducirse de la petición hecha el 6 de febrero de 1328 por el Consell de Orihuela a Alfonso IV para que condonase una parte del servicio de 5.000 sueldos que había solicitado a la aljama mudéjar de la villa con motivo de su coronación. Le recordaban que su padre, Jaime II, les había rebajado dicha cantidad de 5.000 a 2.000 sueldos atendiendo a su precaria situación económica, y, lo que era mucho más grave, a causa de las pechas originadas por la conquista de Cerdeña, muchos moros se habían marchado de la aljama oriolana a vivir a Elche, Crevillente o Abanilla, corriendo el riesgo de que la morería se despoblara ${ }^{20}$. $\mathrm{M}^{\mathrm{a}}$. T. Ferrer recoge la conmoción que entre los sarracenos causaron los impuestos especiales pedidos en 1322 y 1324 para la conquista de Cerdeña en las morerías de Orihuela y Elche. En esta última el éxodo a Granada y Berbería hizo que el rey escribiera el 10 de marzo de 1324 a los viejos y moros ilicitanos interrogándoles por la causa que les llevaba a emigrar, comprometiéndose a que los oficiales reales los tratasen bien y los defendieran, pero aunque en Orihuela se rebajó de 5.000 a 2.000 sueldos la cantidad pedida, ello no impidió que las salidas de población sarracena de la Procuración continuasen en estos años ${ }^{21}$.

Todo apunta a que fueron años muy duros fiscalmente hablando, pues a la subvención de 1322 hubo que añadir una nueva petición en 1324 a las villas de la Procuración, de la que tan sólo sabemos que Orihuela aportó la cantidad de 10.000 sueldos. Una vez más los peor parados eran los musulmanes, que en el caso de Alicante debían contribuir con 2.000 sueldos, pero en vista de su miseria, el rey hubo de rebajarles la exigencia en un cincuenta por ciento, 1.000 sueldos. En parecida situación estaba la exigua comunidad de Orihuela, que en 1328 todavía tenía deudas pendientes por los subsidios que les había exigido Jaime II y pedía al nuevo rey, Alfonso IV, una rebaja de aquellos 5.000 sueldos solicitados hacía años para su coronación, pues muchos moros se habían ido a vivir a otros lugares para no tener que pagar tales cargas, hecho éste que el Consell oriolano se encargó de ratificar en apoyo de la petición de la aljama sarracena de la villa ${ }^{22}$.

Otra consecuencia directa de la campaña sarda y de las dificultades económicas que ello supuso para la monarquía fue la petición hecha por el rey a las villas de las tierras situadas más allá de Jijona de que le adelantasen nuevamente el monedaje, que sería recaudado por el baile general Jaume Andreu y por el baile de Orihuela Jaume Masquefa ${ }^{23}$; problema siempre arduo, pues el realengo iba disminuyendo poco a poco en beneficio del señorío. Vemos, pues, a las minorías musulmana y judía soportando una fuerte presión fiscal, lo que se tradujo a la larga, junto con otros muchos factores, en la extinción de la morería de Orihuela.

20 ACA: cartas reales de Alfonso IV, $n^{\circ}$ 85. FERRER I MALLOL, $M^{a}$ T.: Les aljames sarraïnes de la Governació d'Oriola en el segle XIV. Barcelona, 1988, doc. ํํ 81, pp. 56 y 244-245.

21 FERRER I MALLOL, M. ${ }^{\text {T }}$.: Els sarraïns de la Corona catalano-aragonesa en el segle XIV. Segregació i discriminació, Barcelona, 1987, p. 151.

22 ACA, cartas reales de Alfonso IV, $\mathrm{n}^{\circ}$. 86. (1328, febrero, 6). FERRER I MALLOL, M. ${ }^{\mathrm{a}}$ T.: Les aljames sarraines ..., pp. 164-165.

23 FERRER I MALLOL, M. ${ }^{\text {a }}$., Les aljames sarraïnes ..., p. 162. 
La campaña del infante Alfonso en Cerdeña tuvo también algunas repercusiones en la configuración política y en los cargos de gobierno de la Procuración oriolana, debido a la movilidad de algunos de los personajes que ejercían tales funciones y que se habían desplazado a la isla ante el llamamiento real. Por eso el 15 de diciembre de 1323 Jaime II ordenaba a Maimó Sacirera, lugarteniente del procurador general del reino dellà Sexona, que continuara ejerciendo el cargo a pesar de la muerte en Cerdeña de Pere de Queralt, que lo había nombrado para dicha lugartenencia. En lo sucesivo actuaría en nombre de Bernat de Guimerà, hasta que éste regresara de la isla, puesto que había sido nombrado para sustituir al difunto ${ }^{24}$. Pere de Queralt encontró la muerte en Cerdeña, en el sitio a la villa de Iglesias, antes del 28 de octubre de 1323. Parece que le acompañó en la expedición su hijo Guillem. Al difunto Pere de Queralt le sustituyó en la Procuración oriolana el 28 de octubre de 1323 el noble catalán Bernat de Guimerà, que estaba en Cerdeña cuando le llegó el nombramiento de procurador general de Valencia dellà Xixona. La Lugartenencia continuó ejerciéndola el caballero Maimó Sacirera, puesto que Guimerà es posible que ni siquiera llegara a tomar posesión efectiva de la Procuración. Si el gobierno de Bernat de Guimerà fue efímero, puede decirse otro tanto de su sucesor, Bernat Saportella, otro catalán que también estaba en la empresa sarda, que fue nombrado el 28 de marzo de 1324 para la Procuración, pero falleció el 8 de agosto de ese año, siendo sustituido por el cuñado del rey, Guillem Ramón de Montcada, hermano de la reina Elisenda, desde el 5 de septiembre de $1324^{25}$.

Por otra parte, la marcha del infante Alfonso, el procurador general, a Cerdeña en 1323 tuvo consecuencias para el título del procurador, que hasta entonces había sido, literalmente, de: «portantveus general de l'infant pel que fa a l'ofici de la procuració en la part del regne de València dellà Xixona". Al quedar como portavoz su hermano el infante Pere, el título de procurador del territorio pasó a ser de «lloctinent general de portantveus de governador general en el regne de València dellà Xixonas ${ }^{26}$.

Podemos considerar, en definitiva, que la principal consecuencia que la conquista de Cerdeña tuvo para las localidades de la Procuración de Orihuela fue de índole económico, dado que la aportación humana — si la hubo- es imposible de fijar en el estado actual de nuestros conocimientos. Por un lado, la exacción dineraria solicitada por la Corona a las villas, que éstas intentaron cobrarse consiguiendo que se fijara la modalidad impositiva de las sisas. Éstas no eran nuevas en las comarcas meridionales del reino de Valencia, ya que Jaime II había autorizado en 1307 y 1308 a Orihuela, Alicante, Guardamar y Elche a imponer sisas con el fin de hacer frente a los gastos militares del municipio por causa de su situación fronteriza con el reino de Granada.

24 ACA, C, reg. 233, f. 130r-v. FERRER I MALLOL, M. ${ }^{\mathrm{a}}$ T.: Organització i defensa d'un territori fronterer. La Governació d'Oriola en el segle XIV, Barcelona, 1990, doc. $n^{\circ}$ 117, pp. 446-447.

25 FERRER I MALLOL, M. ${ }^{a}$ T.: Organització i defensa ..., pp. 108-110. Acerca del fallecimiento de Saportella cf. CABEZUELO PLIEGO, J. V., «El veneno en la política. La muerte de Bernat Saportella, procurador de Orihuela, a manos de los patricios", inédito.

26 FERRER I MALLOL, M.ํㅜ., Organització $i$ defensa ..., p. 13. Acerca del cambio de denominación en el reino de Valencia cf. CABEZUELO PLIEGO, J. V., Poder público y administración territorial en el reino de Valencia, 1239-1348. El oficio de la Procuración, en prensa. 
No olvidemos, por otra parte, que este impuesto tenía su precedente en otro llamado "Comune", que se percibía en estas localidades cuando pertenecieron al reino de Murcia, hasta $1296^{27}$. A partir de ahora, la sisa se convertirá en una exacción fiscal regular y en la principal fuente de ingresos para los municipios alicantinos del sur del reino de Valencia ${ }^{28}$.

27 VEAS ARTESEROS, M. ${ }^{\text {a }}$ C., Fiscalidad concejil en la Murcia de fines del Medievo, Murcia, 1991.

28 HINOJOSA MONTALVO, J.: «Finanzas y fiscalidad de las ciudades valencianas», IV Semana de Estudios Medievales, León, 1995, en prensa. 